УДК $615.322+544.653 .2 / .3$

\title{
АНТИОКСИДАНТНЫЕ И ЭЛЕКТРОХИМИЧЕСКИЕ СВОЙСТВА МОНОСУКЦИНАТА ДИГИДРОКВЕРЦЕТИНА - НОВОГО ВОДОРАСТВОРИМОГО ПРОИЗВОДНОГО ПРИРОДНОГО ФЛАВОНОИДА
}

\author{
() Б.Н. Баженов, Г.Д. Елисеева, Е.Е. Золотарев, А.В. Кашевский, А.Ю. Сафронов", \\ Б.Л. Финкельштейн \\ Иркутский государственный университет, ул. К. Маркса, 1, Иркутск, 664003 \\ (Россия), e-mail:dean@chem.isu.ru
}

Моносукцинат дигидрокверцетина - синтезированное производное природного антиоксиданта дигидрокверцетина, имея более высокую растворимость в воде по сравнению с дигидрокверцетином, сохраняет при этом антиоксидантные свойства последнего, что подтверждается ТЕАС методом и данными вольтамперометрических измерений. Электрохимические превращения моносукцината дигидрокверцетина на графитовом электроде имеют при этом более сложную природу, чем у базового флавоноида.

Ключевые слова: моносукцинат дигидрокверцетина, антиоксидантная активность, циклическая вольтамперометрия.

\section{Введение}

Биофлавоноиды в последние 2-3 десятилетия все более эффективно используются для создания лекарственных препаратов, биологически активных и пищевых добавок, обладающих антиоксидантными свойствами [1]. Способность нейтрализовать повреждающее действие активных форм кислорода на молекулярные структуры клеток живого организма, широкий спектр лечебного действия при весьма разнообразных патологиях, ставят эти природные соединения на одно из первых мест в современной фармацевтике.

Биофлавоноид дигидрокверцетин (ДКВ) (I) выделяется среди известных нескольких сотен представителей этого класса соединений своей высокой биологической активностью и широким комплексом надежно доказанных фармакологических применений и превосходит по своей антиоксидантной активности многие из из-

Баженов Борис Николаевич - доцент кафедры общей и неорганической химии, кандидат химических наук, старший научный сотрудник,

e-mail: scorpio1956@mail.ru

Елисеева Галина Дмитриевна - научный сотрудник института нефте- и углехимического синтеза при ИГУ, кандидат химических наук

Золотарёв Егор Евгеньевич - аспирант кафедры общей и неорганической химии, e-mail:

egorzolotarev@yandex.ru

Кашевский Алексей Валерьевич - доцент кафедры общей и неорганической химии, кандидат химических наук, e-mail: caribcar@mail.ru

Сафронов Александр Юрьевич - заведующий кафедрой общей и неорганической химии, доктор химических наук, профессор, тел.: (3952) 52-10-79, факс: (3952) 42-59-35, e-mail: dean@ chem.isu.ru. Финкельштейн Борис Львович - доцент кафедры органической химии, кандидат химических наук вестных препаратов, в том числе - $\alpha$-токоферол и аскорбиновую кислоту. ДКВ, выделяемый из древесины лиственницы сибирской или даурской (Larix sibirica Ledeb. и L. dahurica Turz.), входит в состав ряда фармацевтических препаратов и биологически активных пищевых добавок [2]. На его основе созданы и успешно применяются лекарственные средства, например, «Диквертин» [3]. ДКВ также широко используют в пищевой промышленности (производство шоколада, сухого молока других жиросодержащих продуктов) для придания лечебно-профилактических свойств продукции и для увеличения сроков ее хранения.

Низкая растворимость препарата (как в воде, так и в жирах) препятствует его более широкому использованию в составе инъекционных препаратов, капель, мазей, эмульсий. В связи с этим актуальным

\footnotetext{
* Автор, с которым следует вести переписку.
} 
является получение водорастворимых производных ДКВ с сохранением его антиоксидантного потенциала, чего можно достичь введением гидрофильных структурных фрагментов в молекулу флавоноида, не затрагивающих ее участки, ответственные за антиоксидантные свойства. Одним из таких заместителей может быть остаток янтарной кислоты, связанный с молекулой ДКВ сложноэфирной связью (II).

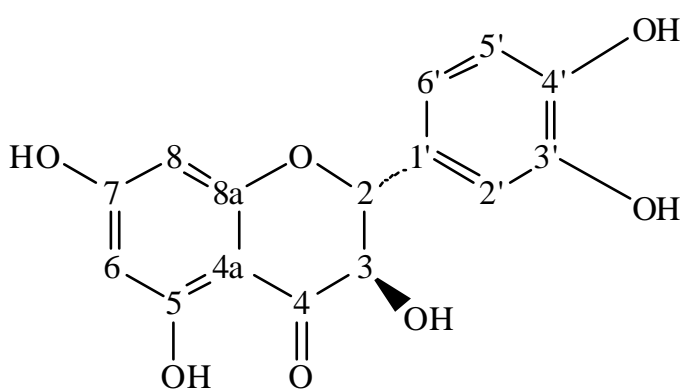

Дигидрокверцетин (I)

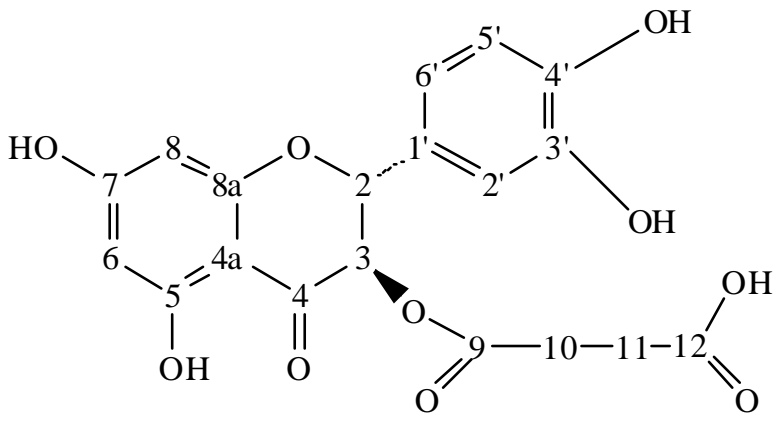

Моносукцинат дигидрокверцетина (II)

Подобный подход к получению новых лекарственных форм в настоящее время уже используется. Например, известно полусинтетическое производное флавоноида силибина - бис-гемисукцината динатриевая соль - хорошо растворимое в воде и применяемое для внутривенного введения при тяжелых интоксикациях печени (торговое название - Легалон СИЛ) [4].

Янтарная кислота, способная образовываться в результате биотрансформаций таких препаратов in vivo, нетоксична и сама участвует в процессах метаболизма. Известны многие растворимые и нерастворимые лекарственные формы, например: «Янтарь-антитокс» - таблетки, «Цитофлавин» - раствор для внутривенного капельного введения и таблетки; «Капли Береш Плюс» - капли для приема внутрь, действующим началом которых является янтарная кислота [1].

Получение новых производных дигидрокверцина и янтарной кислоты позволяет расширить возможности создания новых лекарственных препаратов, обладающих антиоксидантными, капилляро-, гастро- и гепатопротекторными свойствами, а также используемых в комплексной терапии при лечении и профилактике ишемической болезни сердца и других заболеваний.

Электрохимическое поведение дигидрокверцетина изучают довольно активно [5-8], хотя основные особенности механизма его окислительно-восстановительных превращений до сих пор трактуются неоднозначно. Данных об электрохимических свойствах нового производного ДКВ, представленного в данной работе, естественно, обнаружить не удалось.

В связи с вышеизложенным основной целью представляемой работы явилось проведение сравнительного анализа антиоксидантной и электрохимической (окислительно-восстановительной) активности моносукцината дигидрокверцетина и базового исходного флавоноида дигидрокверцетина.

\section{Экспериментальная часть}

В работе использовались реактивы: $\mathrm{KH}_{2} \mathrm{PO}_{4}$ (х.ч., перекристаллизованый из воды), $\mathrm{NaOH} \mathrm{(х.ч.).} \mathrm{Ди-}$ гидрокверцетин с содержанием > 95\% был предоставлен ООО «Флавир» (Иркутск). Для приготовления рабочих растворов применялась бидистиллированая вода.

Синтез моносукиинат дигидроквериетина (МСДКВ). Соединение (II) - светло-желтый порошок получено ацилированием дигидрокверцетина янтарным ангидридом (мольное соотношение $1: 5$ ) в ацетоне в присутствии основания с последующим препаративным выделением целевого продукта [9]. Методом ВЭЖХ (хроматограф НP 1050, колонка 4×150, Силасорб-8С 18 , элюент $\mathrm{MeCN}: \mathrm{H}_{2} \mathrm{O}, 1 \% \mathrm{H}_{3} \mathrm{PO}_{4} 30$ : 70 об.\%) не обнаружено как исходных соединений, так и иных продуктов ацилирования.

Выход 35\%. Т.пл. = 112-114 С. Вычислено, \%: С 56,43; Н 3,96. Найдено, \%: С 57,00; Н 3,99, бруттоформула $\mathrm{C}_{19} \mathrm{H}_{16} \mathrm{O}_{10}$.

ЯМР ${ }^{1} \mathrm{H}\left(500\right.$ МГц, $\mathrm{Me}_{2} \mathrm{CO}-\mathrm{d}_{6}$, м.д., ТМС - 0, Ј/Гц): 5,34 (1H, д, J = 11, H-2), 5,79 (1H, д, J = 11, Н-3), 5,98 (1Н, д, J = 2, Н-6), 6,00 (1H, д, J = 2, H-8), 7,04 (1Н, д, J = 2, H-2’), 6,86 (1H, д, J = 8, Н-5'), 6,87 (1Н, дд, $\mathrm{J}=8$ и 2, Н-6'), 2,52/2,59 (4Н, м, Н-10,11). 
ЯМР ${ }^{13} \mathrm{C}\left(125,1\right.$ МГц, $\left.\mathrm{Me}_{2} \mathrm{CO}-\mathrm{d}_{6}\right)$ : (м.д.) 192,64 (C-4), 167,96 (C-7), 165,08 (C-8a), 165,54 (C-5), 145,8/146,8 (C-3'/4'), 128,25 (C-1'), 120,61 (C-6'), 115,4/116,04 (C-2'/5'), 102,03 (C-4a), 96,33/97,4 (C-6/8), 81,8 (C-2), 73,36 (C-3), 171,41 (C-9), 174,27 (C-12), 29,24/29,13 (C-10/11).

Антиоксидантную активность определяли модифицированным TEAC (Trolox Equivalent Antioxi-

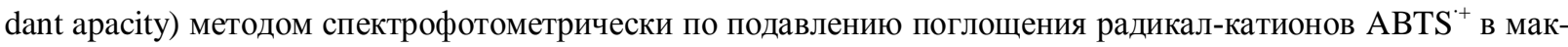
симуме при 730 нм, генерируемых взаимодействием ABTS с персульфатом калия в солевом фосфатном буфере $(\mathrm{pH} 7,4)$ по отношению к тролоксу, активность которого в данном методе принята за единицу [10]. Относительная стандартная ошибка, определенная по результатам нескольких параллельных измерений, составила не более $2,5 \%$.

Для электрохимических измерений использовали установку на базе потенциостата IPC - pro M (Россия); трехэлектродную ячейку объемом 50 мл; графитовый рабочий электрод с площадью видимой поверхности 0,39 см², хлорсеребряный электрод сравнения BAS RE-1; платиновый вспомогательный электрод. Скорости развертки потенциала (v) варьировали от 1 до 500 мB/c. Фосфатно-щелочной буферный раствор готовили из $0,1 \mathrm{M} \mathrm{KH}_{2} \mathrm{PO}_{4}$ добавлением $1 \mathrm{M}$ раствора $\mathrm{NaOH}$, величину $\mathrm{pH}$ определяли при помощи иономера ЭВ-74. Растворы исследованных веществ (все концентрации $-10^{-3}$ моль/л) готовили растворением в фосфатном буфере и переносили в электрохимическую ячейку. Перед измерением вольтамперограмм, раствор в ячейке продували аргоном в течение 10 мин. Все эксперименты выполнены при комнатной температуре.

\section{Обсуждение результатов}

Модификация дигидрокверцетина введением гидрофильного заместителя (остатка янтарной кислоты), как и ожидалось, привела к увеличению растворимости более чем в 40 раз: 1,7 г/л по сравнению с 0,04 г/л для исходного соединения.

Отсутствие гидроксильной группы в 3-м положении у соединения (II) могло бы повлиять на его антиоксидантную активность, однако измеренные величины ТЕАС практически не отличаются: 1,61 и 1,58, для (I) и (II), соответственно.

Так как способность к участию в окислительно-восстановительных реакциях является одним из важнейших проявлений антиоксидантных свойств, основные оценочные параметры антиоксидантной активности МСДКВ были получены методом циклической вольтамперометрии.

Циклические вольтамперограммы МСДКВ, ДКВ и янтарной кислоты представлены на рисунке 1.

Из приведенных вольтамперограмм следует, что янтарная кислота не имеет характеристичных пиков тока в исследованной области потенциалов и, таким образом, электрохимической активности не проявляет. Электрохимическое поведение МСДКВ подобно поведению ДКВ, на что указывает форма и положение катодных и анодных пиков тока на кривых 1 и 2, однако величина тока в пиках окисления и восстановления ДКВ выше, чем у МСДКВ. Общее снижение величины тока на вольтамперограммах 1 и 2 при многократном циклировании незначительно и может быть связано как с изменениями параметров поверхности рабочего электрода, так и с частичной блокировкой поверхности электрода продуктами окисления исследованных веществ. В то же время наиболее характерной электрохимической особенностью МСДКВ, безусловно, является рост катодного тока на кривой 2 в области потенциалов $\mathrm{E} \sim-50 \div 150$ мВ и сопутствующее ему увеличение анодного тока в этой же области потенциалов, особенно заметное на фоне остальных приведенных на рисунке вольтамперограмм. Отсутствующий на всех остальных вольтамперограммах, этот подъем тока может свидетельствовать о возникновении еще одной редокс-пары, характерной только для МСДКВ и не проявляющейся при окислительно-восстановительных превращениях составных частей этого синтетического производного.

Анализ влияния скорости развертки потенциала на величину и положение редокс пиков широко применяется в методе циклической вольтамперометрии и позволяет, в частности, оценить электрохимическую обратимость исследуемых процессов [11]. В случае МСДКВ с ростом скорости развертки потенциала общий вид вольтамперограмм и положение пиков окисления-восстановления не претерпевают принципиальных изменений по сравнению с кривой, измеренной при $\mathrm{v}=20$ мB/c (рис. 1). При этом, однако, наблюдается рост величины $\Delta \mathrm{E}=\mathrm{E}_{\mathrm{p}}{ }^{\mathrm{a}}-\mathrm{E}_{\mathrm{p}}{ }^{\mathrm{k}}$ (где $\mathrm{E}_{\mathrm{p}}{ }^{\mathrm{a}}$ и $\mathrm{E}_{\mathrm{p}}{ }^{\mathrm{k}}$ - потенциалы анодного и катодного пиков, соответственно), пропорциональное возрастанию скорости развертки потенциала. Такая зависимость характерна для квазиобратимых процессов, и в этом, вероятно, проявляется еще одно отличие МСДКВ от его природного аналога, для которого в исследованной области потенциалов была предложена схема электрохимически обратимых окислительно-восстановительных превращений [5]. 
Из представленных на рисунке 2 зависимостей высоты пиков тока окисления и восстановления МСДКВ от скорости развертки потенциала следует, что окислительно-восстановительные превращения МСДКВ на графитовом электроде в исследуемых условиях имеют сложный характер и не отвечают ни одной из классических схем кинетического описания вольтамперометрических измерений [12]. Более того, симметричность представленных зависимостей исключает даже возможные предположения о превалировании одного механизма над другим, так как и кривые 1 и 2, и кривые 3 и 4 примерно в равной степени далеки от линейности. Таким образом, можно лишь предполагать одновременное влияние на процесс диффузии молекул МСДКВ из раствора к поверхности рабочего электрода и кинетического переноса электронов с участием молекул МСДКВ и, возможно, продуктов их редокс-превращений, находящихся непосредственно на электроде или в ближнем приэлектродном пространстве.

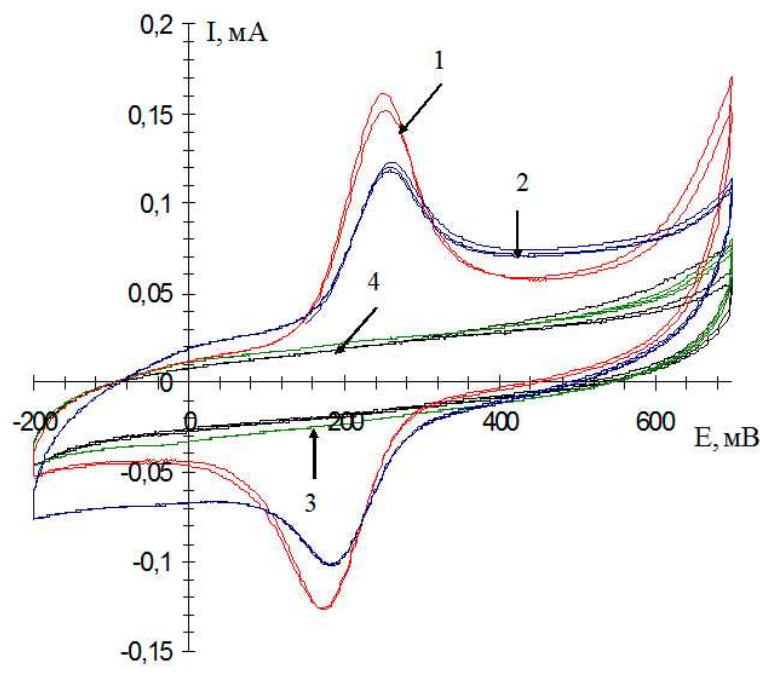

Рис. 1. Циклические вольтамперограммы, измеренные на графитовом электроде в растворах: 1 - ДКВ; 2 - МСДКВ; 3 - янтарной кислоты и 4 - в 0,1 М фосфатном буферном растворе; $\mathrm{pH} 7,0$, концентрации исследованных веществ $10^{-3} \mathrm{M}, \mathrm{v}=20 \mathrm{MB} / \mathrm{c}$

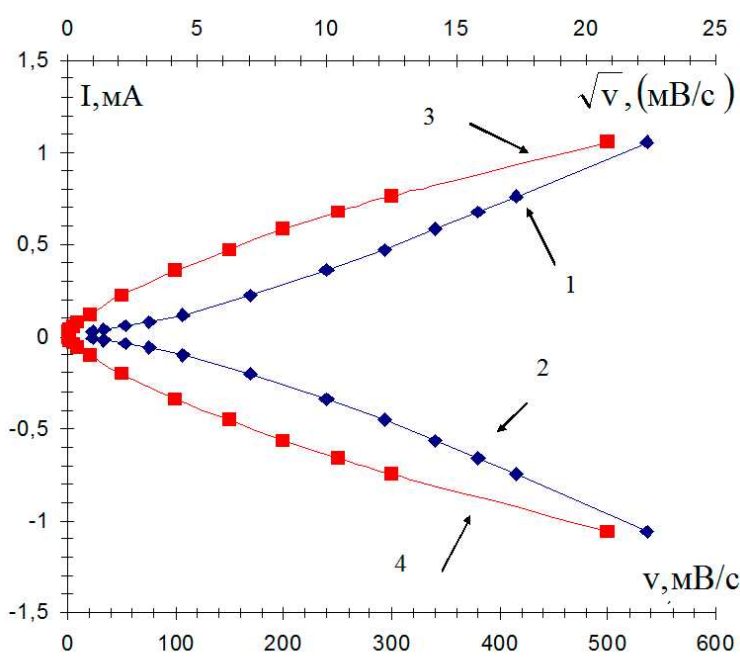

Рис. 2. Зависимость величины тока в катодных $(1,3)$ и анодных $(2,4)$ пиках на вольтамперограммах МСДКВ от: 1, 2 - корня квадратного из скорости развертки потенциала, 3, 4 - скорости развертки потенциала в первой степени

\section{Выводы}

1. Новое синтезированное производное природного антиоксиданта дигидрокверцетина - его моносукцинат, имея серьезное преимущество перед исходным соединением - более высокую растворимость в воде по сравнению с ДКВ, сохраняет при этом антиоксидантные свойства последнего, что подтверждается ТЕАС-методом определения антиоксидантной активности и данными вольтамперометрических измерений.

2. Окислительно-восстановительные превращения моносукцината дигидрокверцетина на графитовом электроде, подтверждая его антиоксидантную активность, имеют при этом сложную природу, понимание которой позволит регулировать формальные электрохимические показатели редокс-активности МСДКВ для конкретных условий и сред.

\section{Список литературы}

1. Internet-версия Государственного рееста лекарственных средств. URL: http://www.drugreg.ru/Bases/WebReestrQuery.asp (дата обращения 03.05.2012).

2. Плотников М.Б., Тюкавкина Н.А., Плотникова Т.М. Лекарственные препараты на основе диквертина. Томск, 2005. $228 \mathrm{c}$.

3. Патент 2088256 (РФ). Средство для комплексной терапии заболеваний «Диквертин» и способ его получения / Н.А. Тюкавкина, В.А. Хуторянский, М.Ю. Сайботалов, Б.Н. Баженов, В.К. Колхир, И.А. Руленко, Ю.А. Колесник. 1997.

4. Patent 2167414A (UK). Silibinin derivatives / R. Braatz, K. Gorler, G. Halbach, H. Soicke, K. Schmidt. 1986. 
5. Janeiro P., Conduneanu O., Brett A.M.O. Chrysin and ( \pm ) - Taxifolin electrochemical oxidation mechanisms // Electroanalysis. 2005. Vol. 17, N12. Pp. 1059-1064.

6. Saito A., Sugisawa A., Umegaki K. Comparison of photometric, electrochemical and post-column fluorescence detection for the determination of flavonoids by HPLC // Shokuhin Eiseigaku Zasshi. 2001. Vol. 42, N3. Pp. 174-178.

7. Jørgensen L., Madsen H., Thomsen M., Dragsted L., Skibsted L. Regeneration of phenolic antioxidants from phenoxyl radicals: an ESR and electrochemical study of antioxidant hierarchy // Free Radical Researsh. 1999. Vol. 30, N3. Pp. 207-220.

8. Матвеев Д.А., Арбузова Е.А., Крайкивский П.Б., Апрелкова Н.Ф., Хуторянский В.А., Крюкова К.М. Электрохимическое восстановление дигидрокверцетина на ртутном электроде // Электрохимия. 2011. Т. 47, №9. C. 1096-1102.

9. Финкельштейн Б.Л., Даниловцева О.С., Баженов Б.Н., Сайботалов М.Ю. Синтез водорастворимых производных дигидрокверцетина и янтарной кислоты и их антиоксидантная активность // Биотехнология растительного сырья, качество и безопасность продуктов питания: материалы докладов Всероссийской научнопрактической конференции, посвященной 80-летию ИрГТУ. Иркутск, 2010. С. 79-83.

10. Re R., Pellegrini N., Proteggente A., Pannala A., Yang M., Rice-Evans C. Antioxidant activity applying an improved ABTS radical cation decolorization assay // Free Radicals Biol. Med. 1999. Vol. 26. Pp. 1231-1237.

11. Brett C.M.A., Brett A.M.O. Electrochemistry: Principles, Methods and Applications. Oxford, 1993. Pp. 174-198.

12. Compton R.G., Banks C.E. Understanding Voltammetry. London, 2011. Pp. 107-152.

Поступило в редакиию 22 мая 2012 2.

После переработки 21 ноября 2012 2.

Bazhenov B.N., Eliseeva G.D., Zolotarev E.E., Kashevskii A.V., Safronov A.Y.", Finkelshtein B.L. THE ANTIOXIDANT AND ELECTROCHEMICAL PROPERTIES OF THE NOVEL WATER SOLUBLE BIOFLAVONOID DERIVATIVE - DIHYDROQUERCETIN MONOSUCCINATE

\section{Irkutsk State University, ul. K. Marksa, 1, Irkutsk, 664003 (Russia),e-mail: dean@chem.isu.ru}

The native antioxidant dihydroquercetin has a wide spectrum of pharmacological properties, however its low solubility make cense for getting the water soluble derivatives maintaining a high antioxidant activity. A possible strategy to get this result could be a hydrophilic moiety (such as succinic acid residue) insertion into the flavonoid molecule. Being more soluble in water the novel synthetic derivative of the bioflavonoid - dihydriquercetin monosuccinate maintains a high antioxidant activity confirmed by means of TEAC method and the voltammetry data. Dihydriquercetin monosuccinate redox transformations on a graphite electrode proving the high antioxidant activity of the studied compound, at the same time demonstrate a complex character. Better understanding of this character is a possible way to the dihydriquercetin monosuccinate redox parameters control under different conditions and/or in the different environments.

Keywords: dihydroquercetin monosuccinate, antioxidant activity, cyclic voltammetry.

\section{References}

1. Internet-versiia Gosudarstvennogo reestra lekarstvennykh sredstv. [Internet-version of the State register of medicines]. URL: http://www.drugreg.ru/Bases/WebReestrQuery.asp. (in Russ.).

2. Plotnikov M.B., Tiukavkina N.A., Plotnikova T.M. Lekarstvennye preparaty na osnove dikvertina. [Medications based on Diquertin.]. Tomsk, 2005. 228 p. (in Russ.).

3. Patent 2088256 (RU). 1997. (in Russ.).

4. Patent 2167414A (UK). 1986.

\footnotetext{
* Corresponding author.
} 
5. Janeiro P., Conduneanu O., Brett A.M.O. Electroanalysis, 2005, vol. 17, no. 12, pp. 1059-1064.

6. Saito A., Sugisawa A., Umegaki K. Shokuhin Eiseigaku Zasshi, 2001, vol. 42, no. 3, pp. 174-178.

7. Jørgensen L., Madsen H., Thomsen M., Dragsted L., Skibsted L. Free Radical Researsh., 1999, vol. 30, no. 3, pp. 207-220.

8. Matveev D.A., Arbuzova E.A., Kraikivskii P.B., Aprelkova N.F., Khutorianskii V.A., Kriukova K.M. Elektrokhimiia, 2011, vol. 47, no. 9, pp. 1096-1102. (in Russ.).

9. Finkel'shtein B.L., Danilovtseva O.S., Bazhenov B.N., Saibotalov M.Iu. Biotekhnologiia rastitel'nogo syr'ia, kachestvo i bezopasnost' produktov pitaniia: materialy dokladov Vserossiiskoi nauchno-prakticheskoi konferentsii, posviashchennoi 80-letiiu IrGTU. [Biotechnology of plant material, the quality and safety of food products: Materials of All-Russian scientific-practical conference dedicated to the 80th anniversary of Irkutsk State Technical University]. Irkutsk, 2010, pp. 79-83. (in Russ.).

10. Re R., Pellegrini N., Proteggente A., Pannala A., Yang M., Rice-Evans C. Free Radicals Biol. Med., 1999, vol. 26, pp. 1231-1237.

11. Brett C.M.A., Brett A.M.O. Electrochemistry: Principles, Methods and Applications, Oxford, 1993, pp. 174-198.

12. Compton R.G., Banks C.E. Understanding Voltammetry, London, 2011, pp. 107-152.

Received May 22, 2012

Revised November 21, 2012 